\title{
Reproductive and lifestyle factors associated with early menopause in Mexican women
}

Paola A. Ortega-Ceballos, MSc, (') Carlos Morán, MSc, (2) Julia Blanco-Muñoz, MSc, ${ }^{(3)}$ Elsa Yunes-Díaz, MSc, ${ }^{(3)}$ Maura S. Castañeda-Iñiguez, MSc, ${ }^{(3)}$ Jorge Salmerón, DSc. ${ }^{(4)}$

\author{
Ortega-Ceballos PA, Morán C, Blanco-Muñoz J, \\ Yunes-Díaz E, Castañeda-Iñiguez MS, Salmerón J. \\ Reproductive and lifestyle factors associated \\ with early menopause in Mexican women. \\ Salud Publica Mex 2006;48:300-307.
}

\begin{abstract}
Objective. The purpose of this study was to evaluate the relationship between certain reproductive and lifestyle factors and the occurrence of early natural menopause. Material and Methods. A case/control study was conducted on a basal population of 2510 women participating in the "Mexican Institute of Social Security health workers cohort study". Cases were defined as those women for whom natural menopause presented by age 47. Information was obtained through a self-administered questionnaire. Results. The risk of early menopause is associated with short menstrual cycles [< 26 days, OR=3.79 (IC 95\%।.37-I0.52)], a short period of oral contraceptives use $[<1$ year, $O R=2.63$ (IC 95\% I.I0-6.29)], a lower number of pregnancies $[<2$, $\mathrm{OR}=1.63$ (IC 95\% I.03-2.57)], low body mass index $[\leq 27$ $\mathrm{kg} / \mathrm{m}^{2}, O R=1.64$ (IC 95\% I.I0-2.43)], low schooling level $[<6$ years, OR=3.02 (IC 95\% I.26-7.23)], smoking history [> I5 cigarettes/day, OR=2.7 (IC 95\% I.00-7.30)], and birth cohorts $[\geq 1950$, OR=4.09 (IC 95\% 2.62-6.39)]. Conclusions. The findings of this study suggest that both reproductive and lifestyle factors are significant elements in the occurrence of early menopause in Mexican women.
\end{abstract}

Keywords: early menopause, reproductive lifestyle factors, Mexico
Ortega-Ceballos PA, Morán C, Blanco-Muñoz J, Yunes-Díaz E, Castañeda-Iñiguez MS, Salmerón J. Factores reproductivos y de estilos de vida asociados con menopausia temprana en mujeres mexicanas. Salud Publica Mex 2006;48:300-307.

\section{Resumen}

Objetivo. Evaluar la relación entre factores reproductivos, estilo de vida y la ocurrencia de menopausia natural temprana. Material y métodos. Un estudio de casos y controles fue conducido en una población basal de 2510 mujeres participantes en la "Cohorte de trabajadores IMSS". Los casos fueron definidos como aquellas mujeres que presentaron la menopausia natural a los 47 años o menos. La información fue colectada a través de cuestionarios autoapicables. $\mathbf{R e}$ sultados. El riesgo de menopausia temprana está asociado con ciclos menstruales cortos $[<26$ días, $R M=3.79$ (IC 95\%।.37-I0.52)], poco tiempo de uso de anticonceptivos orales [<I año, $R M=2.63$ (IC $95 \%$ I.I0-6.29)], bajo número de embarazos [<2, $R M=1.63$ (IC 95\% I.03-2.57)], índice de masa corporal bajo [ $\leq 27 \mathrm{~kg} / \mathrm{m}^{2}, R M=I .64$ (IC 95\% I.I0-2.43)], baja escolaridad [<6 años, $R M=3.02$ (IC 95\% I.26-7.23)], tabaquismo [ $>15$ cigarros/día, $R M=2.7$ (IC 95\% I.00-7.30)], y cohorte de nacimiento $[\geq 1950, R M=4.09$ (IC 95\% 2.62-6.39)]. Conclusiones. Los hallazgos sugieren que tanto factores reproductivos como de estilo de vida son elementos significantes en la ocurrencia de la menopausia a edad temprana en mujeres mexicanas.

Palabras clave: menopausia temprana, factores reproductivos, estilo de vida, México

(I) Secretaría Académica. Instituto Nacional de Salud Pública. Cuernavaca, Morelos, México.

(2) Coordinación de Investigación en Salud. Hospital de Gineco-Obstetricia Luis Castelazo Ayala, Instituto Mexicano del Seguro Social. México, D.F.

(3) Centro de Investigaciones en Salud Poblacional. Instituto Nacional de Salud Pública. Cuernavaca, Morelos, México.

(4) Hospital General Regional No. I. Instituto Mexicano del Seguro Social. Cuernavaca, Morelos, México.

Received on: July 13, 2005 - Accepted on: December 19, 2005

Address reprint requests to: Paola Adanari Ortega Ceballos. Unidad de Investigación Epidemiológica y en Servicios de Salud. Hospital General Regional No. I. Instituto Mexicano del Seguro Social. Avenida Plan de Ayala s/n, esquina Calle Central. 62450 Cuernavaca, Morelos, México. E-mail: portega79@yahoo.com.mx 
M enopause significantly impacts upon the health of women by increasing the risk of chronic illness associated with postmenopausal hormone changes. ${ }^{1-3}$ The altered morbidity profile of postmenopausal women not only decreases their quality of life but also results in a substantial increase in the demand for medical services. ${ }^{2-4}$ Menopause is defined as the permanent cessation of menstruation caused by the loss of follicular activity in the ovaries. ${ }^{1}$ Natural menopause is recognized after 12 consecutive months of amenorrhea with no other pathological or psychological causes. ${ }^{5}$ The average age for the initiation of menopause varies significantly among populations. According to some studies, the mean for the initiation of menopause is 51.4 years in the United States, ${ }^{6} 51$ years in Finland, ${ }^{7}$ and 47 years in Mexico. ${ }^{8}$ Different reproductive factors have been linked to early menopause: early age at menarche, ${ }^{5,9,10}$ short menstrual periods, ${ }^{8,11}$ low use of oral contraceptives, ${ }^{6,12,13}$ low parity, ${ }^{9,14-16}$ and lack of breast feeding. ${ }^{8}$ Some lifestyle factors have also been linked to menopause at an early age, such as a low body mass index (BMI), ${ }^{17,18}$ smoking $^{16,19-22}$ and low schooling level. ${ }^{6,8,12}$ It is possible that differences in the distribution of these factors in the Mexican population may explain the phenomenon of earlier occurrence of menopause. However, there is little information available on the main determinants of early menopause in Mexico. ${ }^{8}$ The objective of this study is to evaluate the link between certain reproductive and lifestyle factors and early menopause in a sample of female employees of the Mexican Institute of Social Security (IMSS, per its abbreviation in Spanish) in the state of Morelos, Mexico.

\section{Material and Methods}

This project consists of a case/control study based on information obtained through baseline measurements from the "IMSS health workers cohort" project carried out between October 1998 and March 2000. The main objective of the IMSS project is to analyze the relationship between lifestyle factors and chronic diseases in the Mexican population. The research was approved in its reevaluation by the National Commission of Scientific Research of the Mexican Institute of Social Security, with registration number 2005-785-012. The female population of the IMSS cohort consists of 2510 active and retired employees of the IMSS health care services in the state of Morelos. Their ages range from 37 to 89 years and the mean age at menopause is $47 \pm 4.4$ years. Due to the nature of the study, individuals with the following characteristics were excluded from the cohort: women under 47 years of age and still menstruating $(62.8 \%)$, pregnant women at the time information was collected $(1.8 \%)$, women who had surgical menopause before age $47(13.2 \%)$, and women with incomplete information on their menopausal condition $(2 \%)$. Also excluded from this study were women for whom premature ovarian failure occurred at an age less than two standard deviations from the mean for the study's population. ${ }^{1}$ This was considered an independent event as analysis excluding these women $(n=16)$ found no changes in the estimators for any of the study variables. A small number of patients presented with diabetes $(n=15)$ but there was no significant association with the risk of early menopause. Out of 507 women $(20.2 \%$ ) who were included, 441 presented natural menopause; for 254 of them it occurred between ages 30 and 47 years, 187 presented it after age 47 and 66 were still menstruating.

Case definition. Women with natural menopause after 12 consecutive months of amenorrhea at age 47 or earlier were defined as cases of early menopause, as has been suggested in other studies. ${ }^{23}$ Two hundred and fifty four cases were obtained in this way. The questions that determined case status in the questionnaire were: Do you currently menstruate? How old were you when you stopped menstruating? How many years ago did you stop menstruating? To distinguish between natural and surgical menopause, the cause of amenorrhea was investigated, with answer options being pregnancy, menopause, or surgery.

Control definition. Women reporting natural menopause after age 47 or who were over 47 years of age and continued menstruating. Two hundred and fifty three controls were thus obtained.

\section{Data collection}

Participants answered a self-administered questionnaire designed to collect information on reproductive history (age at menarche, length of menstrual cycles, length of use of oral contraceptives, number of pregnancies, and duration of breast feeding), demographic characteristics (education, occupation, etc.), body mass index (BMI) at different ages, and certain lifestyle factors (smoking and physical activity). Information was also obtained on age at natural menopause, which was defined as the age at which the last episode of menstrual bleeding occurred and was not followed by another in 12 months. Participants answered the survey without knowledge of the hypothesis of this study and under identical conditions for both cases and controls. The questionnaire 
was manually codified and subsequently captured by optical reading.

\section{Exposure Condition Assessment}

Age at menarche was the reported age of initial menstrual bleeding. Three categories were created for analysis: $<11,11$ to 12 , and $>12$ years. Length of menstrual cycles was defined as the number of days from the first day of menstruation to the beginning of the following period, according to the general characteristics of cycles between the ages of 25 and 35 . The following categories were established as in other studies: ${ }^{9}<26,26$ to 32 , and $>32$ days. Oral contraceptive use was defined as the accumulated time during which women took hormonal contraceptives. The categories for analysis were: $<1,1$ to $<5$, and $\geq 5$ years, as suggested in previous studies. ${ }^{6}$ The categories established for number of pregnancies (including full-term pregnancies) were: $<2$, and $>2$ pregnancies. The cumulative duration of breast feeding was estimated by the sum of total months a woman breast fed her different children. Two categories were created: 0 to 6 months and more than 6 months. The BMI was estimated using the participants' self reports on their height and weight. Information on body image at different ages was also collected, which allowed for an estimation of approximate BMI at the time of menopause, both for cases and controls. Studies conducted in other populations have shown that results of self-perception of body image have a tendency to be similar to those found in direct measurements of size and weight. ${ }^{24}$ The categories for BMI were: $\leq 27 \mathrm{~kg} / \mathrm{m}^{2}$ and $>27 \mathrm{~kg} / \mathrm{m}^{2}$, as has been suggested in other studies. ${ }^{13}$ Education level was estimated using the highest grade achieved as reported by the participants. Three categories resulted: $<6,6$ to 12 , and $>12$ years of education, as described in other studies. ${ }^{14}$ In order to obtain an index of accumulated tobacco exposure, participants estimated the number of cigarettes smoked per day at different ages, from acquiring the habit, until age 40. Using information from other studies, ${ }^{25}$ two categories were established: non-smokers or $\leq 15$ cigarettes and smokers or $>15$ cigarettes per day. Birth cohorts were obtained from the participants' reports of their date of birth. Two categories were thus established: before 1949, and during or after 1950.

\section{Analysis}

The distribution of the different variables in cases and controls was explored. Central tendency measurements were made for continuous variables, and specific ra- tios were estimated for categorical variables by exposure category. The relationship between each of the variables of interest and the occurrence of early menopause was evaluated through logistic regression analysis. Crude and adjusted odds ratios (OR) with confidence intervals $(95 \% \mathrm{CI})$ were estimated for each variable in the study. As a parallel analysis, the age at menopause for all 441 women who presented a natural menopause was analyzed according to specific variables. STATA 7 (Stata Corp., Texas, USA) was used for analysis.

\section{Results}

A total of 254 cases with early menopause were analyzed, having a mean age at menopause of 43.3 years (ranging from 30 to 47 years). Regarding reproductive factors, it was observed that women reporting menarche before age 11 doubled their risk of early menopause compared with women presenting menarche after age 12 . We did not observe a significant association between age at menarche and early menopause (OR=2.13; 95\% CI: 0.64-7.08). Out of the 441 women presenting natural menopause, those presenting menarche before age 11 had menopause 1.8 years before those who presented menarche after age 12 (Figure 1a). Women with a history of short menstrual cycles $(<26$ days) presented a greater risk of early menopause when compared with women having long menstrual cycles (> 32 days) $(\mathrm{OR}=3.79 ; 95 \%$ CI 1.37-10.52) (Table I). Among all women presenting natural menopause, those with short menstrual cycles presented menopause 1.7 years before those with long menstrual cycles (Figure 1a). The average length of oral contraceptive use was 0.7 years longer for controls than for cases, with a mean of 0.6 years for cases and 1.3 years for controls (Table II). Risk of early menopause increased with shorter duration of oral contraceptive use. Women using them for less than a year presented a risk 2.6 times greater than women using them for more than five years ( $\mathrm{RM}=2.63 ; 95 \% \mathrm{CI} 1.10-6.29)$ (Table I). An increased number of pregnancies tended to be inversely associated with risk of early menopause. Women with less than two pregnancies presented an odds ratio of $1.63(95 \%$ CI 1.03 2.57 ) with respect to women having two or more pregnancies (Table I). Women who breast-fed for less than six months had a slight increase in the risk of early menopause with respect to those who breast-fed for more than six months; however, this was not statistically significant (OR=1.28; 95\% CI 0.86-1.90) (Table I).

The percentage of cases and controls with a BMI $\leq 27 \mathrm{~kg} / \mathrm{m}^{2}$ at menopause was $59.8 \%$ and $51.4 \%$, respectively (Table II). Women with a BMI $\leq 27$ at menopause had a $64 \%$ greater risk of early menopause than 
a)

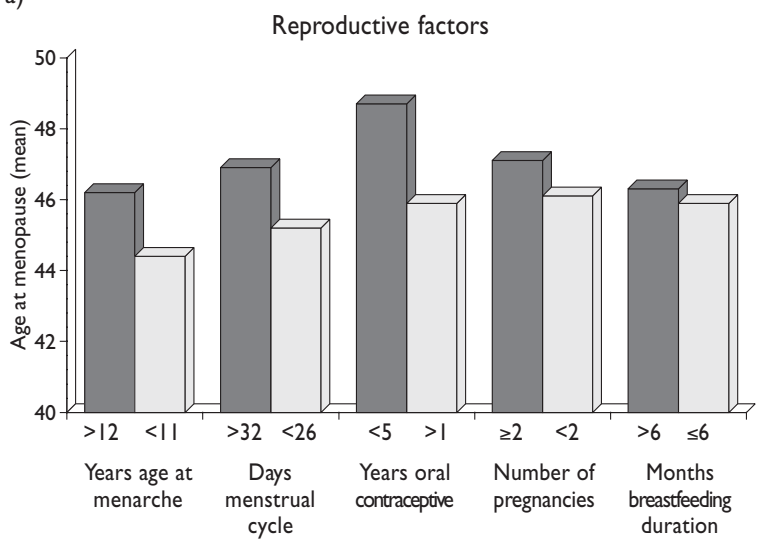

b)

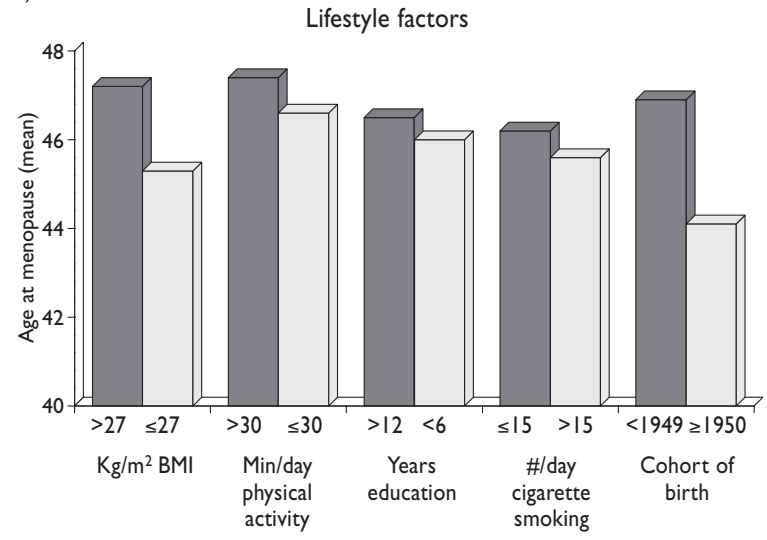

Figure I. Menopause presentation according to reproductive and Lifestyle factors in 44I postmenopausal WOMEN, MeXico

those with a higher BMI (OR=1.64; CI 95\% 1.10-2.43) (Table I). A difference of 1.9 years in age at menopause was found between these categories of BMI (Figure 1b). With regards to schooling, $35.2 \%$ of controls and $26.8 \%$ of cases had achieved a level of more than 12 years, while $4.7 \%$ of controls and $7.5 \%$ of cases had a schooling level of less than 6 years (Table II). Women with a schooling level of 6 to 12 years showed twice the risk of early menopause than women with a schooling level of more than 12 years (OR=2.18; 95\% CI 1.4-3.39). For women with a schooling level of less than six years the risk trebled (OR=3.02; 95\% CI 1.26-7.23) (Table I). In relation to smoking, $3.6 \%$ of controls and $5.1 \%$ of cases smoked more than 15 cigarettes per day before age 40 (Table II). Smokers presented a risk of early menopause almost three times to that of non-smokers $(\mathrm{OR}=2.70 ; 95 \% \mathrm{CI}$ 1.00-7.30) (Table I). On average, smokers presented natural menopause 0.6 years before non-smokers (Figure 1b). The association of physical activity during daily life activities with age at menopause is very similar to the association observed for physical activity during free time. But as this association is not statistically significant $(\mathrm{OR}=0.83$; CI 95\% $0.55-1.25)$, it is not included in the final model. The analysis that was carried out included physical activity during daily life activities, and no changes were found in the estimators for the rest of the variables evaluated.

The percentage of cases and controls belonging to 1950 or later birth cohorts was $41.3 \%$ and $17.4 \%$, respectively. The risk of early menopause for the 1950 or later birth cohorts was four times greater than that of earlier cohorts (OR=4.09; 95\% CI 2.62 - 6.39) (Table I). The difference in the means for age at menopause between these cohorts was 2.8 years (Figure $1 \mathrm{~b}$ ).

\section{Discussion}

The results of this study show inverse associations between different reproductive factors that were considered key determinants of ovulation and risk of early menopause. These factors include age at menarche, length of menstrual cycles, contraceptive use, parity, and breast-feeding. ${ }^{9,12}$ The data presented suggest that some lifestyle factors, such as smoking, low BMI, and low schooling level also carry a greater risk of early menopause. These findings are consistent with the results of previous studies. ${ }^{17,26,27}$ In this study, presentation of menarche at an early age did not have a statistically significant association with early menopause. Studies in the North American population show that women presenting menarche prior to age 11 have a $53 \%$ increase in the risk of early menopause in comparison to women presenting menarche after age $12 .{ }^{5}$ In our study, women presenting menarche before age 11 presented menopause at age 44.4 , and those with menarche after age 12 presented menopause at age 46.2 (Figure 1a). This is consistent with the results of other studies. ${ }^{25}$ Previous studies show that women with short menstrual cycles ( $<26$ days) present menopause two years before those who had longer cycles ( $>32$ days). ${ }^{9,12}$ Our data show similar results with a difference of 1.7 years between both groups (Figure 1a). An association between long menstrual cycles and late menopause has 
Table I

Reproductive and lifestyle factors associated With early menopause in Mexican women

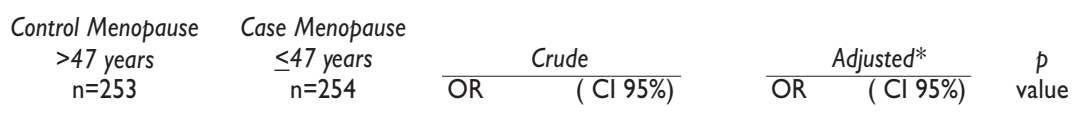

Reproductive factors

Age at menarche (years)

\begin{tabular}{|c|c|c|c|c|c|c|c|}
\hline$>12$ years & 153 & 147 & 1.00 & & 1.00 & & \\
\hline $11-12$ years & 91 & 95 & 1.09 & $(0.75-I .57)$ & 1.06 & $(0.7 I-I .60)$ & 0.75 \\
\hline$<$ II years & 5 & 10 & 2.08 & $(0.69-6.24)$ & 2.13 & $(0.64-7.08)$ & 0.22 \\
\hline
\end{tabular}

Menstrual cycle length (days) $)^{\ddagger}$

\begin{tabular}{|c|c|c|c|c|c|c|c|}
\hline$>32$ days & 19 & 12 & 1.00 & & 1.00 & & \\
\hline $26-32$ days & 212 & 202 & 1.51 & $(0.71-3.19)$ & 1.53 & $(0.67-3.46)$ & 0.32 \\
\hline$<26$ days & 17 & 35 & 3.26 & $(1.29-8.23)$ & 3.79 & $(1.37-10.52)$ & 0.01 \\
\hline
\end{tabular}

Number of pregnancies $\$$

\begin{tabular}{|c|c|c|c|c|c|c|}
\hline$\geq 2$ pregnacies & 201 & 182 & 1.00 & & 1.00 & \\
\hline$<2$ pregnancies & 52 & 72 & 1.53 & $(1.02-2.30)$ & $(1.03-2.57)$ & 0.04 \\
\hline
\end{tabular}

Breast feeding duration (months)

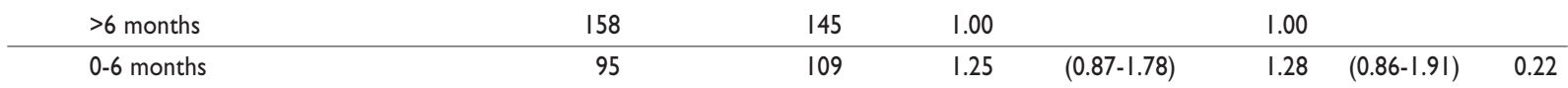

Lifestyle factors

Time of oral contraceptive use (years)

\begin{tabular}{|c|c|c|c|c|c|c|c|}
\hline$\geq 5$ years & 25 & 9 & 1.00 & & 1.00 & & \\
\hline I to $<5$ years & 31 & 26 & 2.33 & $(0.93-5.86)$ & 2.01 & $(0.72-5.56)$ & 0.18 \\
\hline$<$ I year & 197 & 219 & 3.09 & $(1.41-6.78)$ & 2.63 & $(1.10-6.29)$ & 0.03 \\
\hline
\end{tabular}

Body mass index at menopause $\left(\mathrm{kg} / \mathrm{m}^{2}\right)$

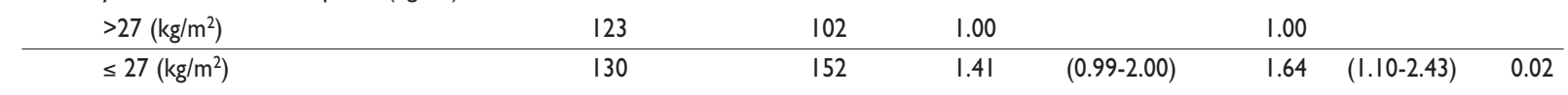

Education (years)

\begin{tabular}{|c|c|c|c|c|c|c|c|}
\hline$>12$ years & 89 & 68 & 1.00 & & 1.00 & & \\
\hline 6 to 12 years & 152 & 167 & 1.44 & $(0.98-2.1 \mathrm{I})$ & 2.18 & $(I .4 I-3.39)$ & 0.00 \\
\hline$<6$ years & 12 & 19 & 2.07 & $(0.94-4.56)$ & 3.02 & $(1.26-7.23)$ & 0.01 \\
\hline
\end{tabular}

Cigarette smoking (among 15 and 40 year olds)

\begin{tabular}{|c|c|c|c|c|c|}
\hline$\leq 15$ cigarettes/day & 235 & 231 & 1.00 & & 1.00 \\
\hline$>15$ cigarettes/day & 9 & 13 & 1.47 & $(0.62-3.50)$ & 2.70 \\
\hline
\end{tabular}

Cohort of birth

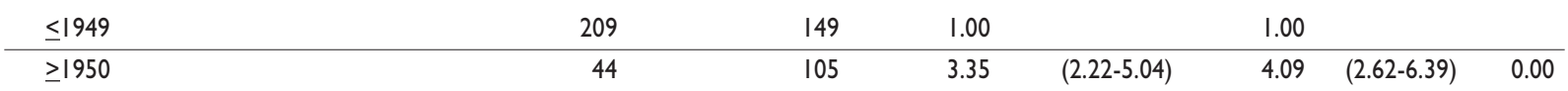

* Odds ratio adjusted for the above variable in the table

‡ Average menstrual cycle length among 20 and 35 years old

$\S$ Adjusted for diabetes, physical activity and above variables excepting breast feeding

\# Adjusted for diabetes, physical activity and above variables except number of pregnancies 
Table II

Distribution of Mexican women at menopause according to Reproductive and lifestyle factors

\begin{tabular}{|c|c|c|c|c|}
\hline & $\begin{array}{l}\text { Control Menopause } \\
>47 \text { years } n=253\end{array}$ & & & $\begin{array}{l}\text { Case Menopause } \\
\leq 47 \text { years } n=254\end{array}$ \\
\hline Mean (SD) & Proportion (\%) & $(95 \% \mathrm{Cl})$ & Mean (SD) & Proportion (\%) \\
\hline
\end{tabular}

Reproductive factors

Age at menarche (years)

$13.0(1.3)$

$12.9(1.4)$

\begin{tabular}{lcccc}
\hline$>12$ years & 60.5 & $(I 3.7-\mid 14.0)$ & 57.9 & $(I 3.8-14.1)$ \\
\hline II-I years & 36.0 & $(I I .7-I I .9)$ & 37.4 & $(I I .7-I I .9)$ \\
\hline$<$ II years & 2.0 & $(I 0.0-10.0)$ & 3.9 & $(9.5-10.2)$ \\
\hline Missing & 1.6 & & 0.8 &
\end{tabular}

Menstrual cycle length (days)* $\quad 30.3(6.8)$

$29.5(6.2)$

\begin{tabular}{lcccc}
\hline$>32$ days & 7.5 & $(45.2-56.4)$ & 4.7 & $(44.8-61.2)$ \\
\hline $26-32$ days & 83.8 & $(26.7-29.0)$ & 79.5 & $(28.6-28.9)$ \\
\hline$<2$ days & 6.7 & $(24.8-25.9)$ & 13.8 & $(24.9-25.9)$ \\
\hline Missing & 2.0 & & 2.0 &
\end{tabular}

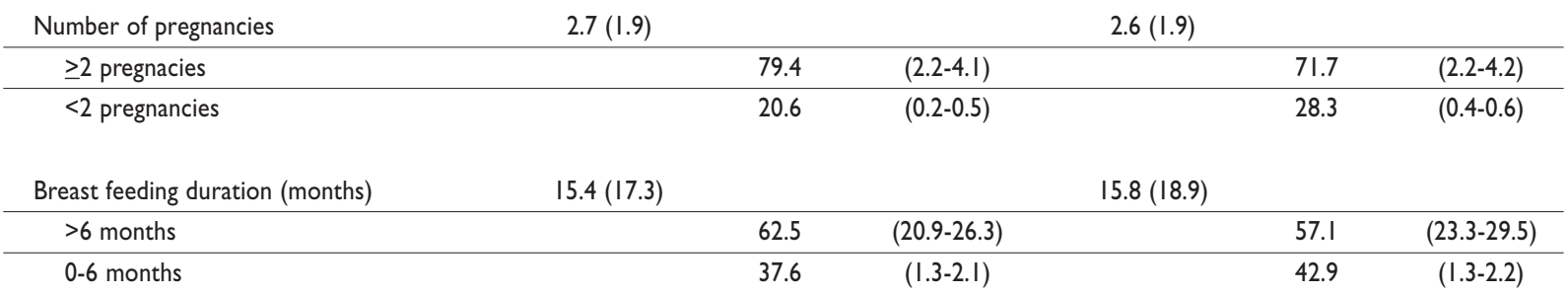

Lifestyle factors

\begin{tabular}{lccccc} 
Time of oral contraceptive use (years) & $1.3(3.1)$ & $0.6(1.9)$ \\
\hline$\geq 5$ years & 9.9 & $(8.4-10.9)$ & 3.5 & $(6.7-11.6)$ \\
\hline I to $<5$ years & 12.3 & $(2.2-2.8)$ & 10.2 & $(2.3-3.1)$ \\
\hline I year & 77.9 & $(0.5-0.9)$ & 86.2 & $(0.3-.07)$
\end{tabular}

\begin{tabular}{|c|c|c|c|c|c|c|}
\hline Body mass index at menopause $\left(\mathrm{kg} / \mathrm{m}^{2}\right)$ & $26.8(3.1)$ & & & $26.6(3.0)$ & & \\
\hline$>27\left(\mathrm{~kg} / \mathrm{m}^{2}\right)$ & & 48.6 & $(28.9-29.6)$ & & 40.2 & $(28.8-29.8)$ \\
\hline$\leq 27\left(\mathrm{~kg} / \mathrm{m}^{2}\right)$ & & 51.4 & $(24.2-24.8)$ & & 59.8 & $(24.5-25.0)$ \\
\hline Education (years) & 12.2(4.8) & & & II.5(4.6) & & \\
\hline$>12$ years & & 35.2 & $(17.3-17.7)$ & & 26.8 & $(|7|-.\mid 7.4)$ \\
\hline 6 to 12 years & & 60.1 & $(9.2-10.2)$ & & 65.7 & $(9.6-10.6)$ \\
\hline$<6$ years & & 4.7 & $(2.8-4.2)$ & & 7.5 & $(3.3-4.6)$ \\
\hline
\end{tabular}

\begin{tabular}{lcccc} 
Cigarette smoking (among I5 and 40 year olds) & $2.1(5.9)$ & $2.7(10.0)$ \\
\hline$\leq 15$ cigarettes/day & 92.9 & $(0.8-1.5)$ & 90.9 & $(0.4-1.0)$ \\
\hline$>15$ cigarettes/day & 3.6 & $(18.7-36.3)$ & 5.1 & $(25.1-52.7)$ \\
\hline Missing & 3.6 & & 3.9 &
\end{tabular}

Cohort of birth

\begin{tabular}{lllll}
$\leq 1949$ & 82.6 & $(1941.2-1943.3)$ & 58.7 & $(1940.3-1942.6)$ \\
\hline$\geq 1950$ & 17.4 & $(1950.3-1950.6)$ & 41.3 & $(1952.3-1953.2)$
\end{tabular}

* Duration average of menstrual cycle among 20 and 35 years old 
been suggested. This is compatible with the idea that menopause occurs after the exhaustion of available follicles. ${ }^{5,9}$ Since early menopause is associated with anovulatory short menstrual cycles ( $<26$ days) and late menopause is associated with anovulatory long menstrual cycles ( $>32$ days), it appears that the age of menopause presentation is not linked directly to anovulation, but to the length of menstrual periods. Analyses among different ethnic groups in the United States have reported that women who took oral contraceptives for a longer period had a lower risk of early menopause than those who had a shorter period of intake.,12 We observed similar results: women who used contraceptives for more than five years presented menopause 2.8 years later than women who used them for less than a year (Figure 1a). A study conducted in Mexico reported an increase in the age at menopause with an increase in the number of children born. ${ }^{15}$ In different populations women who never bore children presented menopause between 0.8 and 1.7 years before those who did. ${ }^{12,14}$ Our findings are consistent with these reports. In addition, social and physical stress have been linked to a greater frequency of anovulatory cycles. ${ }^{28} \mathrm{~A}$ low socioeconomic level or a low schooling level could mark higher stress conditions. ${ }^{6}$ A low socioeconomic level along with an inadequate diet may be linked to the occurrence of early menopause. ${ }^{10,26,29}$ A study of women in the United States reports that among women with a schooling level higher than 12 years, menopause occurred a year after those who received less education. ${ }^{12}$ These results are consistent with ours, where women with a schooling level of less than six years presented menopause five months earlier than those with a schooling level higher than 12 years (Figure 1b). BMI seems to be another determining factor for age at menopause; however, the results found in some studies are inconsistent. Several cross sectional studies did not find an association; $, 6,7,12$ nevertheless, some prospective studies report an inverse association between BMI prior to menopause and a risk of early menopause. ${ }^{17,21}$ Women in the United States in the lowest BMI quintile presented a relative risk of early menopause of 1.15 when compared with women in the highest quintile. ${ }^{17}$ Our findings are similar to those results (OR=1.64; 95\% CI 1.10-2.43). This phenomenon could be explained by a higher estrone production in the adipose tissue of obese women. High levels of circulating estrogens could contribute to prolonging perimenopausal bleeding events. ${ }^{6,17}$

No studies evaluating the link between physical activity and the occurrence of menopause have found a clear association. ${ }^{11,26}$ The association between physical activity and age at menopause observed in our study should be interpreted with some reservations, given that physical activity during the past year may not reflect the usual pattern of physical activity before menopause occurrence.

A link between smoking and early menopause has been found in different studies and in different populations. Studies report that smokers present menopause between six months and two years earlier than nonsmokers. ${ }^{7,14,25}$ In our population smokers presented menopause 0.6 years before non-smokers. Different biological mechanisms have been proposed to explain this association, including toxic effect on ovarian germinal cells, as well as alterations in estrogen metabolism. ${ }^{19}$ Previous studies in Mexican urban populations are scarce. Nevertheless, studies exist that have explored reproductive as well as certain lifestyle variables (age at menarche, number of pregnancies, oral contraceptive use, breast feeding, cigarette smoking, education). ${ }^{8,15,16}$ Our findings are perfectly consistent with those variables studied in previous reports.

The results in our study that compare birth cohorts with regard to age at menopause do not agree with some previous reports. ${ }^{13,14,30-32} \mathrm{~A}$ good explanation for this inconsistency has not been identified. However, it is important to say that some other studies do not find any cohort effect, ${ }^{14}$ nor observe a clear trend across birth cohorts. ${ }^{31}$ This paper reports that the youngest birth cohort (1933-1937) has an adjusted mean of 49.6 years compared to 50.2 years among an older cohort (1928-1932), but then again the adjusted mean age decreases in the same magnitude (adjusted mean age $=$ 49.9) for those in the 1923-1927 birth cohort. Studies from Japan have mainly evaluated women from earlier birth cohorts than our study, so comparison of birth cohorts is made with older ones. ${ }^{31}$

Some findings suggest an inverse association between age at menopause and older birth cohorts. ${ }^{13,30}$ These results may be explained in different ways, but as suggested by the same authors, "it is possible that the difference in early menopause proportions might be attributed to the fact that the early lives of the two generations were differently influenced, in particular, by the second world war and nutritional circumstances" ${ }^{30} \mathrm{An}$ other potential explanation for the differences with our results may be that the previous studies were carried out in much older cohorts than our population, and it may be possible that younger cohorts present an earlier menopause because of the effect of different reproductive and lifestyle patterns (especially with regards to diet and exercise).

Given the importance that age of menopause has on the health of older women, reproductive history and socioeconomic factors have been analyzed in the Mex- 
ican population in previous research. Our results are consistent with the results of those studies. Apart from analyzing these reproductive and socioeconomic factors, other variables were also included that have not been previously analyzed in the Mexican population, such as BMI and birth cohort. The analysis of these additional factors contributes to the knowledge of menopause in the urban Mexican population.

This study found that women who presented early menopause differ from controls in certain reproductive factors such as menarche, length of menstrual cycles, length of use of oral contraceptives and time of pregnancy. At the same time, lifestyle factors such as BMI, schooling and smoking also contribute to the presentation of early menopause. These results may be generalized to the urban working population in Mexico, which represents about $60-70 \%$ of the Country's entire population. Overall, our results suggest that both reproductive factors as well as lifestyle have an important effect in the occurrence of early menopause in Mexican women.

\section{References}

I.World Health Organization. Research on the menopause in the 1990s. Report of a WHO Scientific Group. Technical Report Series No. 866; 1996. 2. Greendale G, Judd H.The menopause: health implications and clinical management. J Am Geriatr Soc 1993;41:426-436.

3.Al-Azzawi F. Endocrinological aspects of the menopause. $\mathrm{Br}$ Med Bull 1992;48: 262-275.

4. Khaw KT. Epidemiology of the menopause. Br Med Bull 1992;48:249-26I. 5. Cramer D, Xu H, Harlow B. Does "incessant" ovulation increase risk for early menopause? Am J Obstet Gynecol 1995; 172:568-573. 6. Gold EB, Bromberg J, Crawford S, Samuels S, Greendale GA, Harlow $\mathrm{SD}$, et al. Factors associated with age at natural menopause in a multiethnic sample of midlife women. Am J Epidemiol 200I;153:865-874.

7. Luoto R, Jaako K, Uutela A.Age at natural menopause and sociodemographic status in Finland.Am J Epidemiol 1994;139:64-67. 8. Garrido F, Lazcano EC, López L, Hernández M. Age of natural menopause among women in Mexico City. Int J Gynecol Obstet 1996;53:159-166.

9. Whelan EA, Sandler DP. Menstrual and reproductive characteristic and age at natural menopause. Am J Epidemiol 1990;131:625-632. 10. Torgerson DJ,Avenell A, Rusell IT, Peid DM. Factors associated with onset of menopause in women aged 45-49. Maturitas 1994;19:83-92. II. Bromberger JT, Matthews KA, Kuller LH, Wing RR, Meilahn RR, Plantinga P. Prospective study of the determinants of age at menopause. Am J Epidemiol 1997; 145: 124-133.

12. Stanford JL, Hartge P, Brinton LA, Hoover RN, Brookmeyer R. Factors influencing the age at natural menopause. J Chronic Dis 1987;40:995-1002.
13. de Vries E, den Tonkelaar I, van Noord PA, van der Schouw YT, te Velde ER, Peerters PH. Oral contraceptive use in relation to age at menopause in the DOM cohort. Hum Reprod 2001;16:1657-1662. 14. Parazzini F, Negri E, La Vecchia C. Reproductive and general lifestyle determinants of age at menopause. Maturitas 1992;15:141-149. 15. Soberon J, Calderon JJ, Goldzieher JW. Relation of parity to age at menopause. Am J Obstet Gynecol 1966; 96:96-100. 16. Alvarado-Zaldivar G, Rivera-Damm R, Ruiz M, Flores-Lozano F, Malacara JM, Forsbach G. Factores que pueden estar asociados con la edad de presentación de la menopausia. Estudio multicéntrico. Ginec Obst Mex 1995;63:432-438.

17. Kato I, Toniolo P. Prospective study of factors influencing the onset of natural menopause. J Clin Epidemiol 1998;52:1290- 292.

18. Von der Recke P, Hansen MA, Hassager C. The association between low bone mass at the menopause and cardiovascular mortality. Am J Med 1999;106:273-278.

19. Baron JA, La Vecchia C, Levi F. The antiestrogenic effect of cigarette smoking in women. Am J Obstet Gynecol 1990;162:502-5I4.

20. Kaufman D, Slone D, Rosenberg L, Miettinen O, Shapiro S. Cigarette smoking and age at natural menopause. Am J Public Health 1980; 70:420-422.

2I.Willett W, Stampfer MJ, Bain C, Lipnick R, Speizer FE, Rosner B, et al. Cigarette smoking, relative weight, and menopause. Am J Epidemiol 1983;| |17:65I-658.

22.Windham GC, Elkin EP, Swan SH,Waller KO, Fenster L. Cigarette smoking and effects on menstrual function. Obstet Gynecol 1999;39:59-65.

23. Dorman JS, Steenkiste AR, Foley TP, Strotmeyer ES, Burke JP, Kuller $\mathrm{LH}$, et al . Menopause in type I diabetic women: is it premature? Diabetes 2001;50:1857-1862.

24. Madrigal-Fritsch H, Irala-Estévez J, Martínez-González MA, Kearney J, Gibney M, Martínez-Hernández JA. Percepción de la imagen corporal como aproximación cualitativa al estado de nutrición. Salud Publica Mex 1999;41:479-486.

25. Meschia M, Pansini F, Modena AB, de Aloysio D, Gambacciani M, Parazzini $F$, et al. Determinants of age at menopause in Italy: results from a large cross-sectional study. Maturitas 2000;34:1 19-125.

26. Nagata C, Takatsuka N, Kawakami N, Shimizu H. Association of diet with the onset of menopause in Japanese women. Am J Epidemiol 2000;152:863-867.

27. Barret E, Trudy M, Bush L. Estrogen and coronary heart disease in women. JAMA 1991; 265:1861-1867.

28. Nilsson P, Möller L, Koster A, Hollnagel H. Social and biological predictors of early menopause: a model for premature aging.J Inter Med 1997;242:299-305.

29. Nagata C, Takatsuka N, Inaba S, Kawakami N, Shimizu H. Association of diet and other lifestyle with onset of menopause in Japanese women. Maturitas 1998;29:105-II3.

30. Cassou B, Derriennic F, Monfort C, Dell'Accio P, Touranchet A. Risk factors of early menopause in two generations of gainfully employed French women. Maturitas 1997;26:165-174.

31 . Kono S, Sunagawa $Y$, Higa H, Sunagawa H. Age of menopause in Japanese women: trends and recent changes. Maturitas 1990;12:43-49. 32. Do K, Treloar S, Pandeya N, Purdie D, Green A, Heath A, et al. Predictive factors of age at menopause in a large Australian twin study. Hum Biol 1998; 70:1073-1091. 